\title{
A simple equation for obtaining finite strain solutions from small strain analyses of tunnels with very large convergences
}

\author{
A. VRAKAS* and G. ANAGNOSTOU*
}

\begin{abstract}
This paper presents a novel, very simple, accurate, theoretically well-founded and widely applicable relationship expressing the tunnel convergences obtained from large strain elasto-plastic analyses as a hyperbolic function solely of the corresponding small strain convergences. It can thus be used for 'selfcorrecting' small strain solutions, removing the need for large strain elasto-plastic analyses at least at the preliminary design stage and quantifying a hitherto unknown error caused by disregarding the geometric non-linearity. The proposed relationship can be proved rigorously for the plane strain rotationally symmetric ground response problem with a general elasto-plastic constitutive law with or without dilatancy and hardening. Numerical analyses of characteristic two- and three-dimensional excavation problems show that this relationship is generally applicable, irrespective of the in situ stress state and the tunnel geometry. It is therefore very useful from an engineering point of view for the design of tunnels crossing heavily squeezing ground, where the convergences may be so large (sometimes well in excess of $10 \%$ of the tunnel radius) that the usual small strain elasto-plastic analyses are deficient.
\end{abstract}

KEYWORDS: deformation; excavation; mining; rock mechanics; theoretical analysis; tunnels

\section{INTRODUCTION}

In problems involving large deformations where the undeformed (initial) and the deformed (current) configuration of the continuum differ significantly, small strain theory, which evaluates both stiffness and equilibrium in the undeformed configuration, leads to erroneous and sometimes even nonsensical results. For example, the widely applied relationships for the ground response curve, which are based upon small strain theory, predict radial displacements $u_{a}$ that are even greater than the excavated radius $a_{0}$ under conditions of very low stiffness and strength and high in situ stress $\sigma_{0}$. This can easily be verified from the Kirsch problem (Fig. 1(a)). The nature of the deficiency in the small strain formulation is the same as in the simple problem of an elastic bar under axial compression, where disregarding the geometric non-linearity may (depending on the ratio of the applied force to the bar's axial stiffness) lead to a displacement greater than the initial bar's length (Fig. 1(b)). The simple example of Fig. 1(a) makes it evident that small strain theory overestimates excavation-induced displacements in the case of large deformations (cf. Pan, 1988; Pan et al., 1989).

Small strain theory remains sufficient, at least from an engineering point of view, as long as strains do not exceed $10 \%$. This condition is fulfilled in the great majority of tunnelling projects. When tunnelling through weak rocks under a high overburden, however, larger convergences may take place. As illustrated by several case studies and detailed reviews (see among others Kovári (1998) and Barla (2002)), a major reduction in the cross-section beyond the planned values represents the main hazard scenario when tunnelling under so-called squeezing conditions. Fig. 2 shows some characteristic examples worldwide where the observed tunnel convergences exceeded one tenth of the excavated tunnel radius.

The occasionally very large deformation phenomena seen in tunnelling, together with the lack of a comprehensive work

Manuscript received 19 February 2015; revised manuscript accepted 23 June 2015. Published online ahead of print 14 August 2015.

Discussion on this paper closes on 1 April 2016, for further details see p. ii.

* ETH Zurich, Zurich, Switzerland. in the literature dealing with their analysis (cf., e.g., review papers by Barla (2002), Mair (2008) and Standing \& Potts (2008)), motivated the present authors to study the response of deep underground openings in the framework of finite strain elasto-plasticity and to derive exact, finite strain, closed-form solutions for the ground characteristic line (Vrakas \& Anagnostou, 2014, 2015).

The present paper shows that the cavity wall displacements $u_{a, \mathrm{ss}}$ obtained from a small strain analysis can be used directly to estimate the displacements $u_{a, \text { ls }}$ that would result from a large strain analysis. More specifically, the paper shows that the classic problem of the ground response curve of a cylindrical (or spherical) cavity exhibits the following interesting property: the normalised cavity convergence $U_{a, \mathrm{ls}}(=$ $u_{a, \mathrm{l} s} / a_{0}$, where $a_{0}$ denotes the tunnel radius) obtained from a large strain analysis can be expressed as a hyperbolic function solely of the normalised cavity convergence $U_{a, \mathrm{ss}}\left(=u_{a, \mathrm{ss}} / a_{0}\right)$ obtained from small strain analysis

$$
U_{a, \mathrm{ls}}=h\left(U_{a, \mathrm{ss}}\right)=1-\frac{1}{\sqrt{1+2 U_{a, \mathrm{ss}}}}
$$

What is particularly interesting about equation (1), however, is that it is also sufficiently accurate for general plane strain excavation problems as well as for the three-dimensional problem of an advancing tunnel heading, irrespective of the constitutive behaviour, the initial stress field and the tunnel cross-section. Consequently, equation (1) can be applied not only to estimate errors in routine small strain analyses, but also to 'self-correct' their results, removing the need for large strain numerical analyses, at least at the preliminary design stage.

The paper starts with an illustration of the practical importance of taking finite strains into consideration by discussing comparative computations covering selected examples of tunnels through heavily squeezing ground. Subsequently, a rigorous mathematical proof of equation (1) is presented for the rotationally symmetric, plane-strain problem of a circular tunnel in an elastic-perfectly plastic, non-dilatant material. Afterwards, it is shown that equation (1) is sufficiently accurate also for a dry material exhibiting dilatant or hardening behaviour, as well as for the instantaneous response of a 


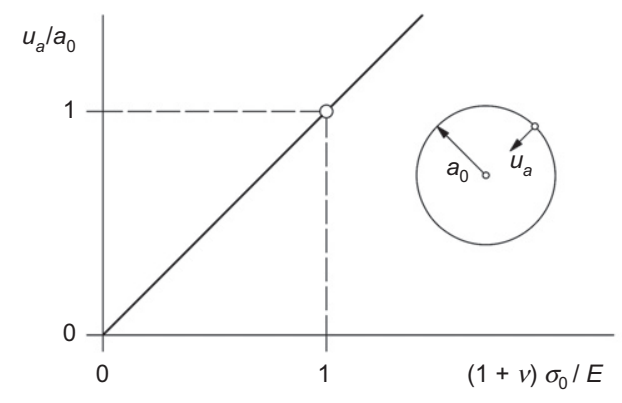

(a)

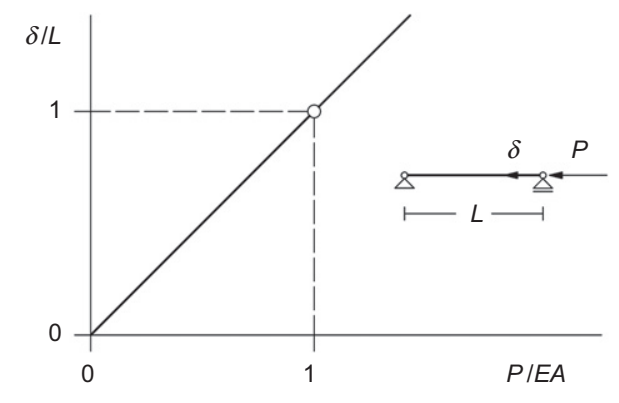

(b)

Fig. 1. Response disregarding the geometric non-linearity that is imposed by the large displacement: (a) wall displacement of an unsupported tunnel according to Kirsch's solution; (b) uniaxial compression of a bar of axial stiffness $E A$

saturated, hardening material, provided that the hardening is completed (or the critical state is reached) at strains of up to $10 \%$, in either axially or spherically symmetric conditions. Finally, the authors close by presenting the applicability of equation (1) to general plane-strain excavation problems and to the three-dimensional problem of an advancing tunnel heading.

\section{SIGNIFICANCE OF LARGE STRAIN FORMULATION \\ The Gotthard base tunnel}

The $57 \mathrm{~km}$ Gotthard base tunnel in Switzerland involves an approximately $6 \mathrm{~km}$ long section crossing rocks of low strength and high deformability (so-called kakiritic rocks) at depths of up to $900 \mathrm{~m}$ (Kovári et al., 2000). Extensive laboratory tests on core samples were carried out at ETH Zurich in the design stage and during construction (Vogelhuber, 2007; Anagnostou et al., 2008), providing valuable information with respect to the rock behaviour and material constants. Fig. 3 shows the ground response curves for typical rock parameters. At the support pressures of practical interest (a few hundred $\mathrm{kPa}$ provided by a yielding support; Cantieni \& Anagnostou (2009)), the small strain analysis strikingly overestimates the wall displacements. From an engineering viewpoint, this implies a need for additional over-excavation in order to maintain the desired clearance (and thus greater deformation capacity in the yielding support). For example, with a desired clearance $a=5 \mathrm{~m}$ under a support pressure $\sigma_{a}=750 \mathrm{kPa}$ (Fig. 3), the required excavation radius $a_{0}\left(=a /\left(1-U_{a}\right)\right)$ equals $8.3 \mathrm{~m}$ according to small strain theory (corresponding to an over-excavation volume of $138 \mathrm{~m}^{3}$ per linear metre), while according to large strain theory it equals $6.7 \mathrm{~m}$ (corresponding to an overexcavation volume of $62 \mathrm{~m}^{3}$ per linear metre, which is $55 \%$ less).

\section{The Yacambú-Quibor tunnel}

The Yacambú-Quibor water transmission tunnel in Venezuela $(500 \mathrm{~km}$ west of Caracas) crosses a distance of $23.3 \mathrm{~km}$ through the Andes. Extreme squeezing conditions, owing to the presence of very weak graphitic phyllites at depths of up to $1270 \mathrm{~m}$, were encountered during excavation, which was finally completed after 32 years (Hoek \& Guevara, 2009). The cross-section closed completely in several locations along the tunnel alignment (Darling, 1992; Fig. 2(b)). The present authors performed a back-analysis of the observed response in order to estimate the cohesion of the graphitic phyllites. Fig. 4 shows the back-calculated cohesion as a function of tunnel convergence, with an unsupported opening. Small strain analysis leads to an overestimation of the strength. Specifically, it reproduces the observed complete closure of the opening (convergence $>80 \%$ ) for cohesion of about $1.3 \mathrm{MPa}$, while the inclusion of large deformation effects leads to cohesion of just $0 \cdot 35 \mathrm{MPa}$. (It is worth noting that graphitic phyllites may cause severe squeezing problems even at depths of cover as little as $45 \mathrm{~m}$; Fig. 2(f).)

\section{The Gibraltar Strait tunnel}

The third example is that of the planned 38-km-long underwater Gibraltar Strait tunnel between Europe and Africa. The presence of two large breccia zones in the middle of the alignment (prevailing over a tunnel section more than $4 \mathrm{~km}$ long and lying $500 \mathrm{~m}$ below sea level and $200 \mathrm{~m}$ below the seabed) calls into question the technical feasibility of the project (Lombardi et al., 2009). Experiments performed at the ETH Zurich (Dong et al., 2013) on samples taken from the project site have confirmed the high deformability, low strength and low permeability of the breccias, which resemble a normally consolidated or slightly over-consolidated soil. Therefore, the short-term convergences and ground pressures developing in the vicinity of the tunnel face are decisive with respect to the risk of the tunnel boring machine's shield jamming. The undrained ground response curves (Fig. 5) support the hypothesis of heavily squeezing conditions and show that the small strain solution greatly overestimates the convergences, even leading to results that are irrational (convergence $>100 \%$ ) at very low support pressures.

\section{THEORETICAL PRELIMINARIES}

A basic consideration facilitating the following mathematical proofs is that the elastic strains of the materials of interest (hard soils and weak rocks) are considerably smaller than the plastic strains (because the yield stress, e.g. the uniaxial compressive strength $\sigma_{\mathrm{D}}$, is small compared with the elastic stiffness, e.g. the Young's modulus E), which implies that large strains are almost entirely due to plasticity. Therefore, the derivations disregard elastic strains in the plastic zone. Exact computations without this simplifying assumption lead to the same relationship between large and small strain solutions (Appendix).

The fact that the elastic strains are small is also relevant for the numerical analysis of general problems with rotating principal directions, as it allows the use of a large deformation plasticity formulation that is based on the additive decomposition of the rate of deformation tensor (i.e. of the symmetric part of the spatial velocity gradient tensor) into elastic and plastic parts. The constitutive equations then relate an objective rate of the Cauchy (or Kirchhoff) stress tensor to the rate of deformation tensor, with the elastic response being hypo-elastic (i.e. non-conservative in a closed 


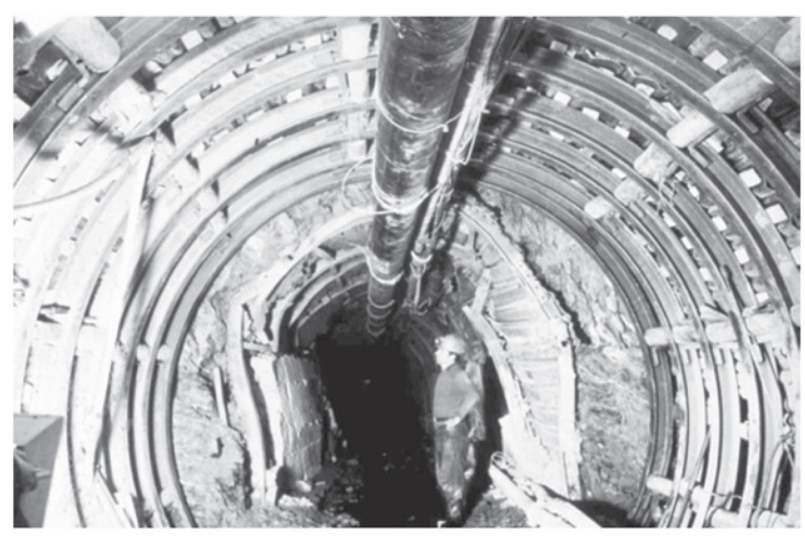

(a)

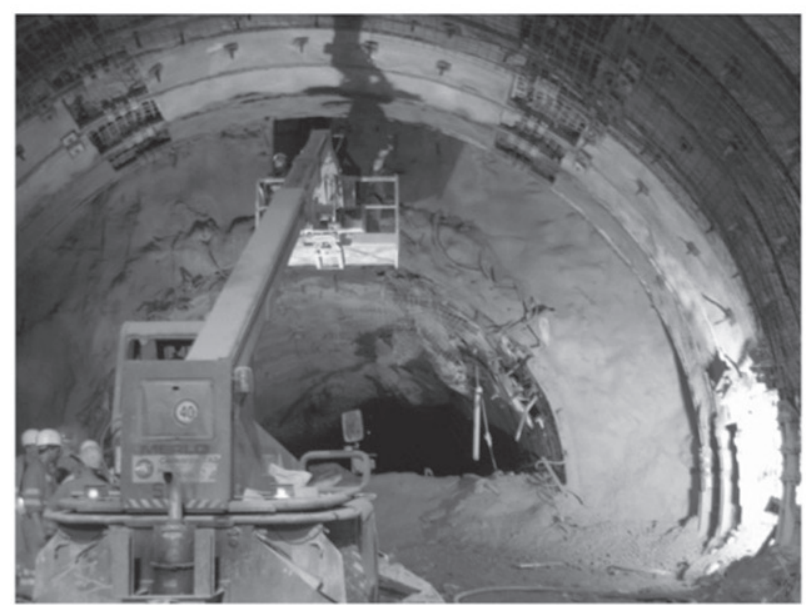

(c)

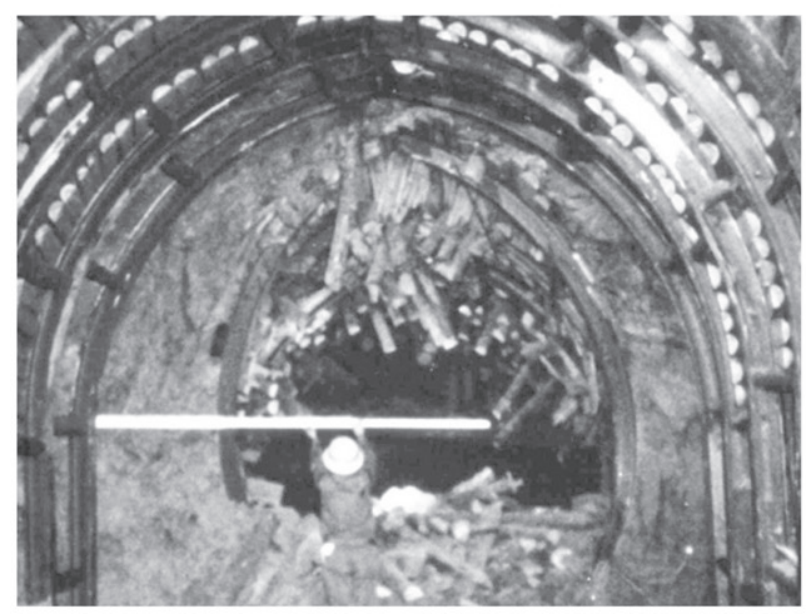

(e)

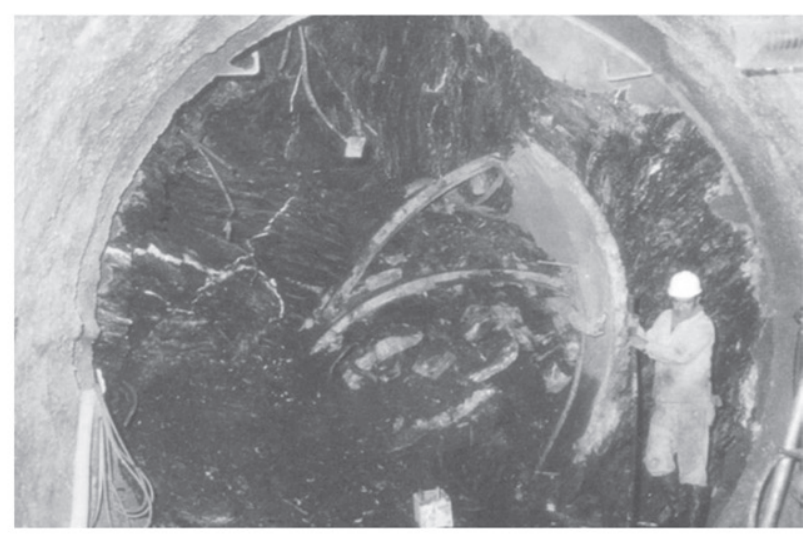

(b)

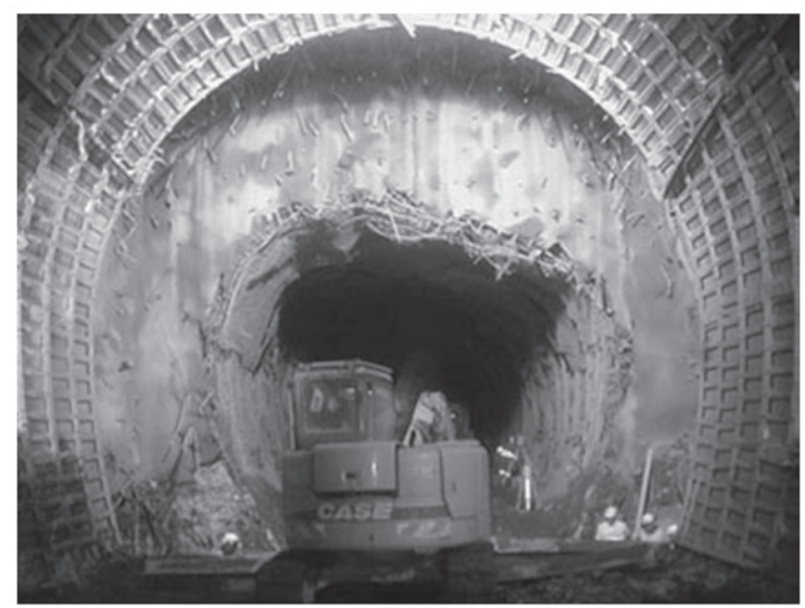

(d)

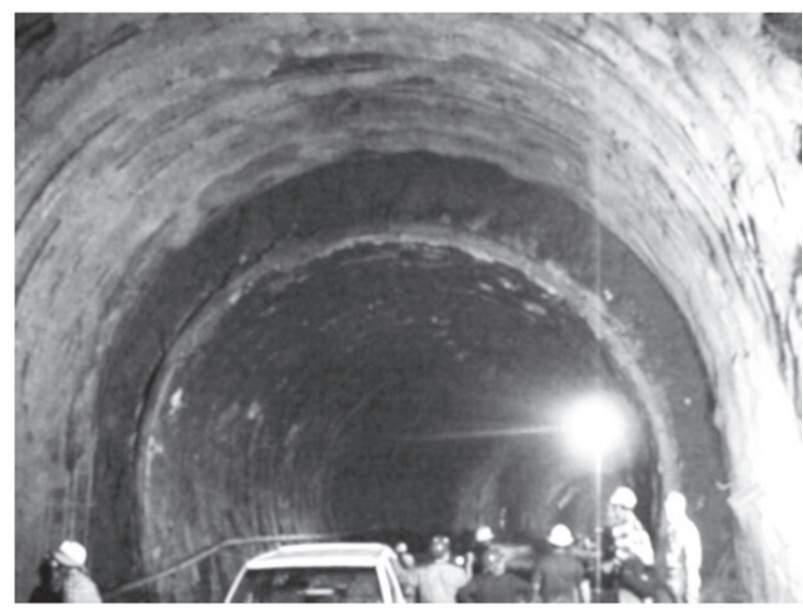

(f)

Fig. 2. Examples of tunnels with very large deformations: (a) safety gallery of the Gotthard motorway tunnel, Switzerland; (b) Yacambú-Quibor tunnel, Venezuela; (c) Faido, Gotthard base tunnel, Switzerland; (d) Saint Martin La Porte access adit, Lyon-Turin base tunnel, France (Barla et al., 2011); (e) Nakayama tunnel, Japan; (f) Canoas tunnel, Venezuela

cycle), even in the case of constant elastic moduli (see, among others, Simo \& Hughes (1998) and Belytschko et al. (2014) for a detailed overall treatment of elasto-plasticity at finite strains).

\section{DERIVATION OF THE PROPOSED RELATIONSHIP Problem definition}

The plane strain problem is considered of a circular, uniformly supported tunnel cross-section in homogeneous, isotropic, elasto-plastic and non-dilatant ground with a homogeneous and isotropic initial stress field (Fig. 6).
Under these conditions, the problem is rotationally symmetric and the tunnel convergence uniform. In the following derivation, compressive stresses and strains and inward radial displacements are taken as positive, while the subscripts 'ss' and 'ls' are used to differentiate between the small and large strain formulation variables.

\section{Kinematic considerations}

Upon unloading, the ground response is elastic until the failure criterion is reached at the tunnel wall. At lower support pressures, the ground around the opening experiences 


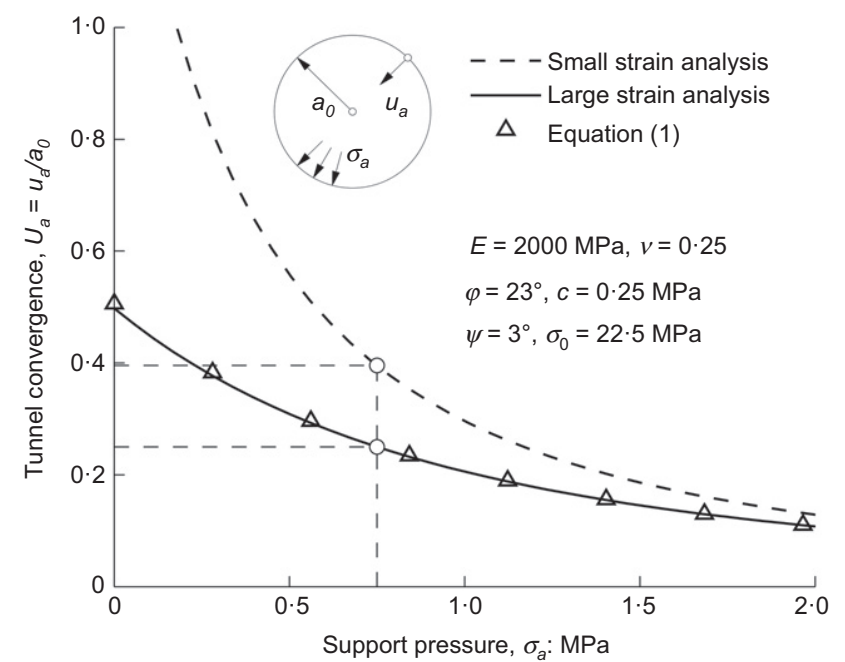

Fig. 3. Ground response curves for the Sedrun section of the Gotthard base tunnel (material constants of the kakiritic rocks after Kovári et al. (2000); computational method after Vrakas \& Anagnostou (2014))

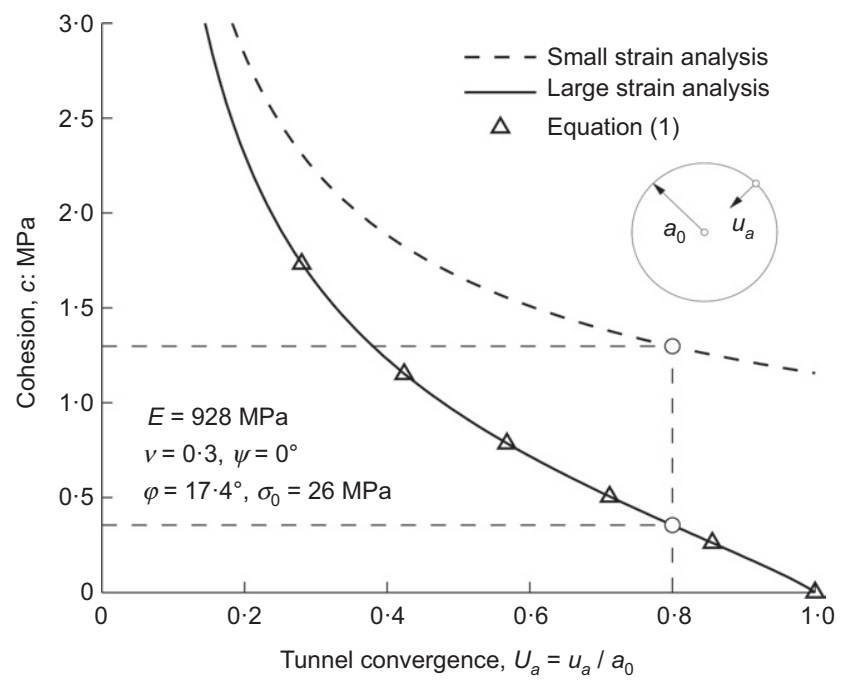

Fig. 4. Back-calculated cohesion of the graphitic phyllites encountered in the Yacambú-Quibor tunnel as a function of tunnel convergence under unsupported conditions (other material constants of graphitic phyllites after Hoek \& Guevara (2009); computational method after Vrakas \& Anagnostou (2014))

increasing irreversible strains and forms an expanding plastic ring of outer radius $\rho_{\text {ls }}$ (large strain solution; Fig. 6(a)) or $\rho_{\text {ss }}$ (small strain solution; Fig. 6(b)). The assumption of zero plastic dilatancy in combination with the negligible elastic volumetric strains within the plastic zone results in deformations under a constant volume, thus making the problem kinematically determinate (Hill, 1950). Specifically, the volume of the plastic ring is equal to its volume in the undeformed state. In the large strain analysis, this means that the two shaded areas in Fig. 6(a) are equal

$$
a_{0}^{2}-a^{2}=\rho_{0,1 \mathrm{~s}}^{2}-\rho_{\mathrm{ls}}^{2}
$$

where $a$ and $\rho_{0,1 \mathrm{~s}}$ denote the radius of the deformed tunnel (current radius) and the radius of the plastic zone in the undeformed configuration, respectively. By definition

$$
\begin{aligned}
& a=a_{0}-u_{a, \mathrm{ls}} \\
& \rho_{0, \mathrm{ls}}=\rho_{\mathrm{ls}}+u_{\rho, \mathrm{ls}}
\end{aligned}
$$

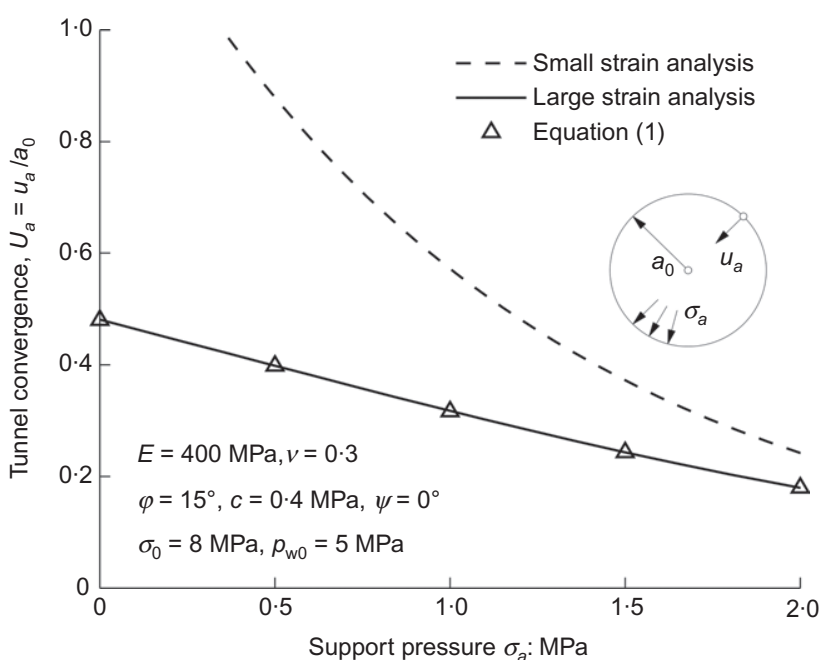

Fig. 5. Undrained ground response curves for the breccia zones of the planned Gibraltar Strait tunnel (material constants of the breccias after Anagnostou (2014); computational method after Vrakas \& Anagnostou (2015))

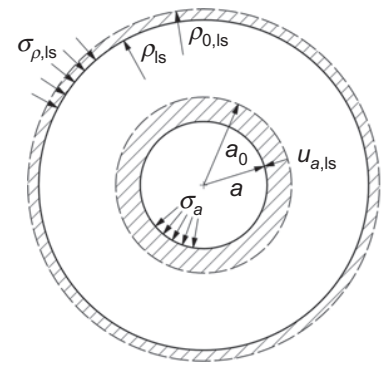

(a)

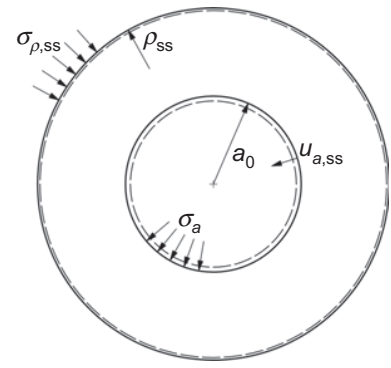

(b)
Fig. 6. Set-up of the plane strain axially symmetric excavation problem for: (a) large strain formulation; (b) small strain formulation

where $u_{\rho, \mathrm{s}}$ denotes the displacement at the elasto-plastic interface. In a small strain analysis (Fig. 6(b)) the respective volumes are approximately equal to the product of the perimeter length on the corresponding radial displacement and, consequently

$$
u_{a, \mathrm{ss}} a_{0}=u_{\rho, \mathrm{ss}} \rho_{\mathrm{ss}}
$$

At the elasto-plastic boundary, the tangential strain

$$
\varepsilon_{t \rho, \mathrm{ss}}=\frac{u_{\rho, \mathrm{ss}}}{\rho_{\mathrm{ss}}}
$$

which in combination with equation (5) leads to

$$
U_{a, \mathrm{ss}}=\left(\frac{\rho_{\mathrm{ss}}}{a_{0}}\right)^{2} \varepsilon_{t \rho, \mathrm{ss}}
$$

In the large strain analysis, the kinematic relationship for the tangential strain reads as follows

$$
\varepsilon_{t \rho, \mathrm{ls}}=\ln \left(1+\frac{u_{\rho, \mathrm{ls}}}{\rho_{\mathrm{ls}}}\right)
$$

which, as the elastic strains are small, simplifies to

$$
\varepsilon_{t \rho, \mathrm{ls}} \cong \frac{u_{\rho, \mathrm{ls}}}{\rho_{\mathrm{ls}}}
$$

Taking account of equations (4) and (9) and neglecting the second-order terms of $\varepsilon_{t \rho, \text { ls }}$ (since the elastic strains are 
small), equation (2) becomes

$$
a_{0}^{2}-a^{2}=\rho_{\mathrm{ls}}^{2}\left(1+\varepsilon_{t \rho, \mathrm{ls}}\right)^{2}-\rho_{\mathrm{ls}}^{2} \cong 2 \varepsilon_{t \rho, \mathrm{ls}} \rho_{\mathrm{ls}}^{2}
$$

which leads, using equation (3), to

$$
U_{a, \mathrm{ls}}=1-\frac{1}{\sqrt{1+2\left(\rho_{\mathrm{ls}} / a\right)^{2} \varepsilon_{t \rho, \mathrm{ls}}}}
$$

\section{Static considerations}

It is assumed that the material behaviour is elasticperfectly plastic and the failure criterion does not depend on the intermediate principal stress. Consequently, the major principal stress can be expressed as an arbitrary function of the minor principal stress, which is commonly the case in rock mechanics. The stress field in the plastic zone satisfies both the failure criterion

$$
\sigma_{t}=f\left(\sigma_{r}\right)
$$

and the equilibrium condition

$$
\frac{\mathrm{d} \sigma_{r}}{\mathrm{~d} r}+\frac{\sigma_{r}-\sigma_{t}}{r}=0
$$

where $\sigma_{r}$ and $\sigma_{t}$ denote the radial and the tangential Cauchy stress (force per current unit area), respectively. (Note that the large strain formulation - in contrast to the small strain formulation - refers to the current geometry and thus the radius $r$ corresponds to the deformed state.) These equations lead to a differential equation for the radial stress

$$
\frac{\mathrm{d} \sigma_{r}}{\sigma_{r}-f\left(\sigma_{r}\right)}+\frac{\mathrm{d} r}{r}=0
$$

whose integration over the plastic zone, that is, over $\left[a_{0}, \rho_{\mathrm{ss}}\right]$ for the small strain formulation and over $\left[a, \rho_{\mathrm{ls}}\right]$ for the large strain formulation, yields

$$
\ln \frac{\rho_{\mathrm{ss}}}{a_{0}}=-\int_{a_{0}}^{\rho_{\mathrm{ss}}} \frac{\mathrm{d} \sigma_{r}}{\sigma_{r}-f\left(\sigma_{r}\right)}=F\left(\sigma_{a}\right)-F\left(\sigma_{\rho, \mathrm{ss}}\right)
$$

and

$$
\ln \frac{\rho_{\mathrm{ls}}}{a}=-\int_{a}^{\rho_{\mathrm{ls}}} \frac{\mathrm{d} \sigma_{r}}{\sigma_{r}-f\left(\sigma_{r}\right)}=F\left(\sigma_{a}\right)-F\left(\sigma_{\rho, \mathrm{ls}}\right)
$$

respectively, where $F$ stands for the indefinite integral of the function $1 /\left[\sigma_{r}-f\left(\sigma_{r}\right)\right] ; \sigma_{a}$ is the applied support pressure (boundary condition), while $\sigma_{\rho, \text { ss }}$ and $\sigma_{\rho, \text { ls }}$ denote the radial stresses at the elasto-plastic boundary (Fig. 6). The latter are determined by considering the outer elastic zone to be at the onset of plastification; that is, the radial stress and the elastically computed tangential stress at the inner boundary of the elastic zone satisfy the yield condition. Since the strains in the elastic zone are small also in the large strain formulation, there is no difference between the large and the small strain formulation with respect to the stress field in the elastic zone. Consequently, the radial stress and the tangential strain at the elasto-plastic interface of the large strain formulation will be equal to those of the small strain formulation (although the plastic radii are different)

$$
\begin{aligned}
& \sigma_{\rho, \mathrm{ls}} \cong \sigma_{\rho, \mathrm{ss}} \\
& \varepsilon_{t \rho, \mathrm{ls}} \cong \varepsilon_{t \rho, \mathrm{ss}}
\end{aligned}
$$

Owing to equation (17), the right-hand sides of equations (15) and (16) are equal

$$
\frac{\rho_{\mathrm{ls}}}{a}=\frac{\rho_{\mathrm{ss}}}{a_{0}}
$$

Equations (7), (11), (18) and (19) lead to equation (1), according to which the normalised tunnel convergence from large strain analysis can be expressed as a function solely of the normalised tunnel convergence from small strain analysis for any support pressure $\sigma_{a}$ (uppermost solid curve in Fig. 7). The hyperbolic function $h$ (equation (1)) satisfies all of the required conditions for theoretical consistency: $h(0)=0$, $h(\infty)=1, h^{\prime}(0)=1, h^{\prime}(\infty)=0, h^{\prime}\left(U_{a, \mathrm{ss}}\right)>0$ and $h^{\prime \prime}\left(U_{a, \mathrm{ss}}\right)<0$. Fig. 7 includes the line $U_{a, \text { ls }}=U_{a, \mathrm{ss}}$ for the purpose of illustrating the error in small strain analyses. The error clearly becomes large for $U_{a \text {,ss }}$ greater than $10 \%$. Note that when the small strain solution $U_{a, \text { ss }}$ is equal to unity (representing a total cavity closure), the actual convergence $U_{a, \text { ls }}$ amounts to just $30-40 \%$, while when $U_{a, \mathrm{ss}}$ tends to infinity, $U_{a, \mathrm{ls}}$ approaches unity.

\section{Relationship for dilatant behaviour and cylindrical or spherical openings}

Considering the slightly more general problem of the ground response curve of a cylindrical or spherical cavity in an elasto-plastic but dilatant ground, the following relationship between small and large strain convergence is obtained (see the Appendix)

$$
U_{a, \mathrm{ls}}=h\left(U_{a, \mathrm{ss}}\right)=1-\frac{1}{\left[1+(\zeta \kappa+1) U_{a, \mathrm{ss}}\right]^{1 /(\zeta \kappa+1)}}
$$

where $\zeta=1$ for the plane strain problem of a cylindrical tunnel, $\zeta=2$ for the spherical cavity problem and $\kappa$ denotes the so-called loosening factor (Kovári, 1985), a function of the dilation angle $\psi(\kappa=(1+\sin \psi) /(1-\sin \psi))$.

According to equation (20), the error induced by the assumption of small deformations depends on the small strain convergence for a given opening type and dilation angle. It should be noted that the small strain theory overestimates not only the convergence, but also the plastic radius (see the Appendix).

Figure 7 provides a graphic representation of equation (20). For the plane strain problem of a non-dilatant material $(\zeta=\kappa=1)$, equation (20) simplifies to the proposed equation (1), which is sufficiently accurate from an engineering viewpoint also for dilatant materials, particularly as weak rocks exhibit low dilation angles (for example, the dilation angle of the above-mentioned kakiritic rocks is lower than $5^{\circ}$; Vogelhuber (2007)), and spherically symmetric conditions. In any case, equation (1) provides an approximation, which is

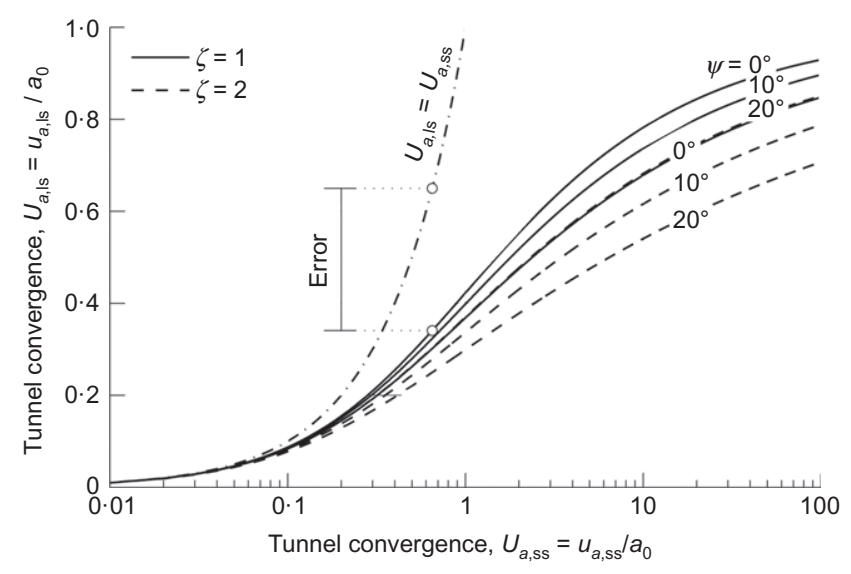

Fig. 7. Normalised large strain convergence $U_{a, \mathrm{ls}}$ as a function of the normalised small strain convergence $U_{a, \mathrm{ss}}$ for several dilation angles, under plane strain rotationally symmetric $(\zeta=1)$ and spherically symmetric $(\zeta=2)$ conditions (equation (20)) 
slightly on the safe side, as it constitutes the upper bound of the family of curves generated by equation (20).

\section{Hardening material behaviour}

Equation (1) was shown to be valid for the case of perfectly plastic material behaviour. This equation also applies, however, for hardening behaviour, provided that failure conditions (i.e. conditions of perfect plasticity) are reached at strains of up to $10 \%$. The proof is basically the same as that presented above. Around a tunnel through hardening material, three ring-shaped zones develop at low support pressures: an inner perfectly plastic zone; an outer hardening plastic zone; and an outer elastic zone. Under the condition that hardening ends at strains lower than $10 \%$, there is no significant difference between the small and finite strain solutions with respect to the two outer zones (and thus the stresses and strains at the interface between the two plastic rings are practically the same, although the position of the interface is different), while the inner plastic ring is treated in the proof in exactly the same way as the plastic zone of the perfectly plastic material in the previous sections. Consequently, all of the given equations also hold for a hardening material with $\rho$ corresponding to the outer radius of the inner plastic zone.

\section{Undrained ground response}

Finally, it should be mentioned that equation (1) also applies for the instantaneous response of saturated lowpermeability grounds, where deformations occur under constant volume. This is obvious when analysing the instantaneous ground response in terms of total stresses considering a perfectly plastic Tresca model. However, it is true even for an effective stress analysis with a non-perfectly plastic constitutive model, provided that critical state conditions are reached at strains less than $10 \%$. The proof is analogous to the previous section. Specifically, in the present case, also, three zones develop at low support pressures: an inner plastic ring, where the material is at critical state (constant deviatoric stress $\sigma_{t}-\sigma_{r}$ ); an outer hardening plastic ring; and an elastic zone. Following the same argument as above, and taking $\rho$ equal to the outer radius of the critical state zone, all of the equations of the previous sections hold.

\section{PLANE STRAIN PROBLEMS NOT OBEYING ROTATIONAL SYMMETRY}

Encouraged by the results of Schürch \& Anagnostou (2012), according to which the rotationally symmetric solution produces a reasonable prediction of average tunnel convergence in plane strain problems that violate rotational symmetry (and are thus not susceptible to analytical solutions), the present authors investigated the applicability of equation (1) to such problems. To this end, a large series of finite-element analyses was performed (512 in total) covering a wide range of conditions (initial stress field, material constants and tunnel cross-section) and the small and large strain analysis results were compared.

The tunnel cross-sections and parameter values are given in the inset of Fig. 8. A uniform (but anisotropic) initial stress field was assumed, given that the gravity effect is negligible in deep tunnels. The ground was taken as a linearly elastic and perfectly plastic material obeying the linear Mohr-Coulomb

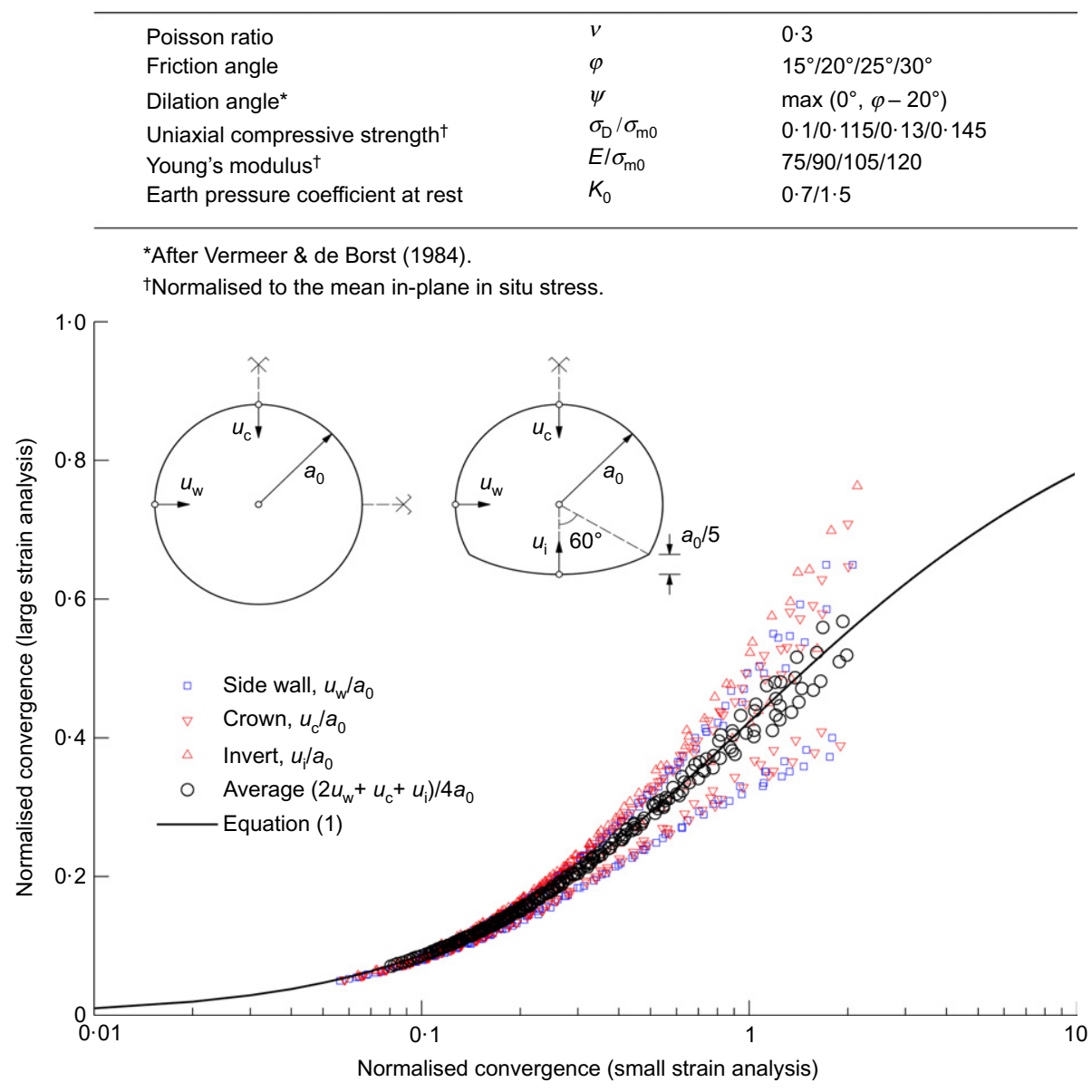

Fig. 8. Relationship between the convergences predicted from small and large deformation plane strain numerical analyses of a circular and a non-circular tunnel cross-section subject to anisotropic initial stresses 
yield criterion. This model is widely used in engineering practice. However, it should be emphasised that the validity of equation (1) is not restricted to this constitutive behaviour. Stress boundary conditions were applied at the far boundaries, $50 a_{0}$, from the centre of the tunnels. The numerical computations were performed by the Abaqus finite-element code (Dassault Systèmes, 2012), using the stress-point algorithm after Clausen et al. (2007).

Figure 8 presents the displacements obtained by small and large strain numerical analyses (horizontal and vertical diagram axis, respectively), normalised to the tunnel radius $a_{0}$. In addition to the horizontal convergence at the side walls (square marks) and the vertical convergences at the crown (downward-pointing triangles) and at the invert (upwardpointing triangles; relevant only for the non-circular tunnel), the average horizontal and vertical tunnel convergences of the cross-section are also depicted (circular marks).

The results of the finite-element analyses are close to the solid curve, which was computed by means of equation (1), thus confirming that this equation describes the relationship between small and large strain convergences very well. The agreement is excellent for the average horizontal and vertical tunnel convergence (circular marks). The individual horizontal or vertical convergences deviate from the proposed relationship by about $10 \%$ in most cases (up to $25 \%$ in exceptional cases of extremely large deformations), being either underestimated (points above the solid curve) or overestimated (points below the solid curve). However, as the error in the small strain assumption is much higher (e.g. at $U_{a, \mathrm{ss}}=1$ it reads $150 \%$ ), equation (1) provides an estimate of actual convergences that is far more accurate than the small strain predictions.

\section{THREE-DIMENSIONAL PROBLEM OF AN ADVANCING TUNNEL HEADING}

A specific example is provided herein to show that equation (1) remains sufficiently accurate for the threedimensional problem of successive step-by-step tunnel excavation. A non-circular cross-section is considered (inset of Fig. 9). The final tunnel length amounts to $50 a_{0}$. The tunnel is excavated in 100 steps (i.e. the round length is equal to $a_{0} / 2$ ), while the model is $100 a_{0}$ long. Stress boundary conditions are applied at the far boundaries, placed $50 a_{0}$ from the tunnel axis, while axial displacements are restrained at the vertical boundaries.

Figure 9 shows the normalised average tunnel convergence along the longitudinal direction. As in the two-dimensional problem, the small strain solution (dashed curve) gives higher convergences than the large strain solution (solid curve). However, the application of equation (1) to the small strain analysis results in an accurate estimate of the wall convergences (circular marks). The reason for this is that the displacements in the vicinity of the tunnel face are relatively small (due to the support provided by the core ahead of the tunnel face) and thus practically equal for both deformation formulations, while the convergences far behind the face are similar to those of the plane strain model, where equation (1) has already been shown to be exact (see previous section).

\section{CONCLUSIONS}

The authors have presented a novel, very simple, accurate, theoretically well-founded and widely applicable relationship for quantifying the error caused by the assumption of small deformations in the analysis of tunnels with very large deformations. This relationship expresses large strain convergences as a hyperbolic function solely of small strain convergences and therefore makes it possible to account for geometric non-linearity in a direct and simple way: by applying a correction factor to the small strain analyses results, that is, 'self-correcting' them. This is very useful from an engineering viewpoint since it allows a quick estimate to be made of the aforementioned error, removing the need for rigorous large strain elasto-plastic analyses, at least at the preliminary design stage.

The proposed relationship has been proved for the plane strain rotationally symmetric problem. However, by

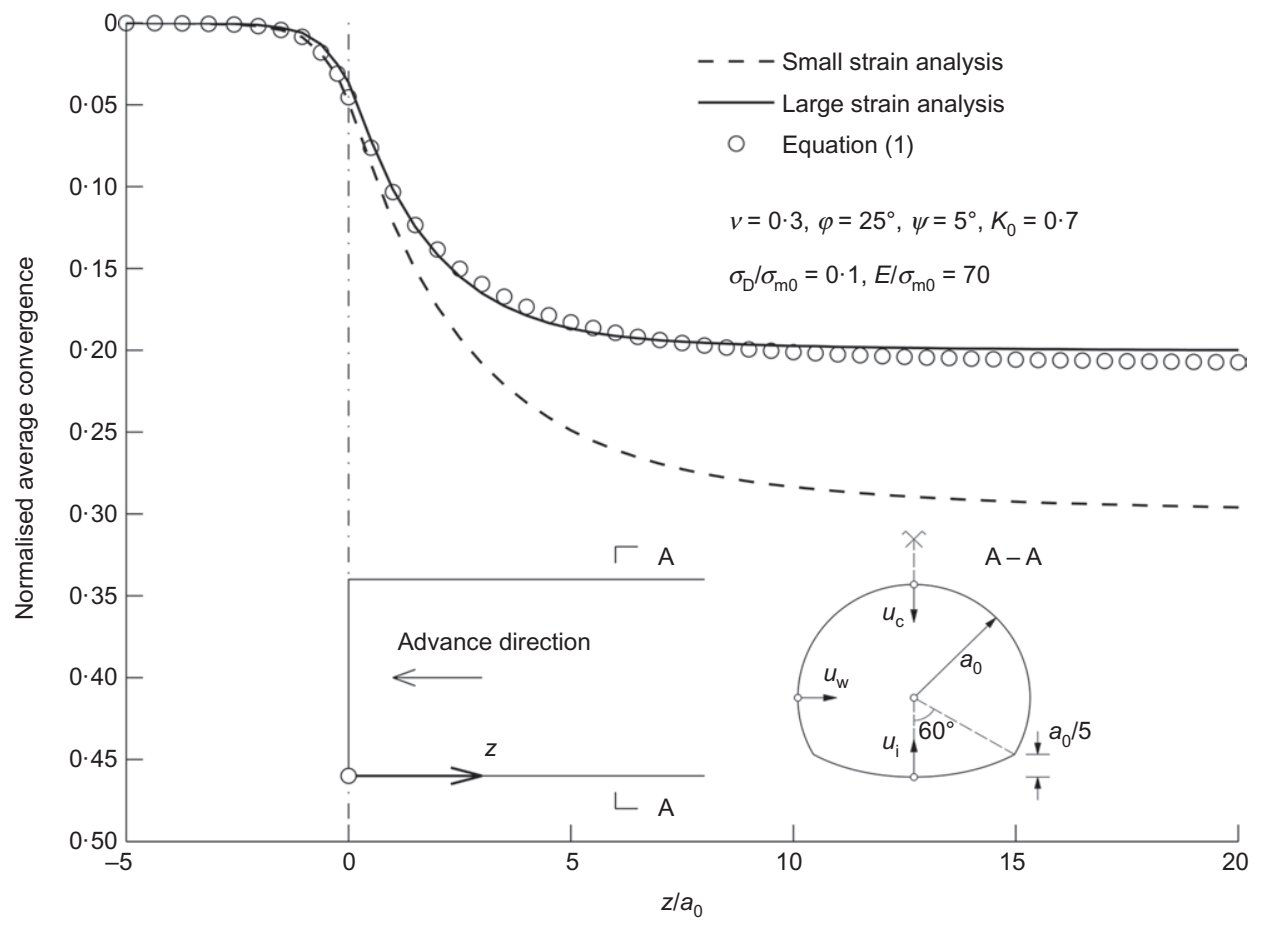

Fig. 9. Normalised average convergence $\left(2 u_{\mathrm{w}}+u_{\mathrm{c}}+u_{\mathrm{i}}\right) / 4 a_{0}$ along the axis of a non-circular tunnel subject to anisotropic initial stresses, predicted from small and large strain three-dimensional numerical analyses 
comparing the deformations according to small strain theory with those resulting from large strain numerical analyses it was found that equation (1) is reasonably accurate also for general two- and three-dimensional excavation problems.

\section{ACKNOWLEDGEMENTS}

This paper evolved within the framework of the research project 'Analysis of large deformation problems in tunnelling considering geometric nonlinearities', which is being performed at the ETH Zurich with the financing of the Swiss National Science Foundation (SNF) under project no. 200021_153433.

\section{APPENDIX. DERIVATION OF EQUATION (20)}

This Appendix presents the derivation of the relationship between small and large strain convergence (equation (20)) for plane strain rotationally symmetric or spherically symmetric conditions and dilatant behaviour. The cylindrical problem is analysed here together with the spherical one by introducing a variable $\zeta$, which is equal to 1 or 2 , respectively.

The assumption is made of constant plastic dilatancy (defined by the loosening factor $\kappa$ ), that is, plastic deformations are accompanied by volumetric changes. The plastic flow rule then implies that the ratio of plastic strain rates is constant

$$
\frac{\mathrm{d} \varepsilon_{r}^{\mathrm{pl}}}{\mathrm{d} \varepsilon_{t}^{\mathrm{pl}}}=-\zeta \kappa
$$

Integrating equation (21) over the elasto-plastic stress history of a material point and considering that elastic strains are negligible inside the plastic zone relative to plastic strains, the flow rule fixes the ratio of total strains

$$
\frac{\varepsilon_{r}}{\varepsilon_{t}} \cong \frac{\varepsilon_{r}^{\mathrm{pl}}}{\varepsilon_{t}^{\mathrm{pl}}}=-\zeta \kappa
$$

In a small strain analysis, the kinematic relationships read as follows

$$
\varepsilon_{r, \mathrm{ss}}=\frac{\mathrm{d} u_{\mathrm{ss}}}{\mathrm{d} r}, \varepsilon_{t, \mathrm{ss}}=\frac{u_{\mathrm{ss}}}{r}
$$

Substituting equation (23) into equation (22) leads to a differential equation for radial displacement, the integration of which provides a very simple relationship between the displacements at the excavation boundary and at the elasto-plastic interface (Kovári, 1985, 1998)

$$
u_{a, \mathrm{ss}} a_{0}^{\zeta \kappa}=u_{\rho, \mathrm{ss}} \rho_{\mathrm{ss}}^{\zeta \kappa}
$$

which for $\kappa=1$ expresses the incompressibility condition (equation (5)). If the tangential strain at the elasto-plastic interface (equation (6)) is also taken into account, equation (24) is written as

$$
U_{a, \mathrm{ss}}=\varepsilon_{t \rho, \mathrm{ss}}\left(\frac{\rho_{\mathrm{ss}}}{a_{0}}\right)^{\zeta \kappa+1}
$$

In the large deformation analysis, logarithmic strains are used; these are appropriate for problems with fixed principal directions as they represent the time integrals of the deformation rates (note also that the additive decomposition of the rate of deformation tensor can then be derived exactly from the multiplicative decomposition of the deformation gradient; Lee (1969))

$$
\varepsilon_{r, \mathrm{ls}}=\ln \frac{\mathrm{d} r_{0}}{\mathrm{~d} r}=\ln \left(1+\frac{\mathrm{d} u_{\mathrm{ls}}}{\mathrm{d} r}\right), \varepsilon_{t, \mathrm{ls}}=\ln \frac{r_{0}}{r}=\ln \left(1+\frac{u_{\mathrm{ls}}}{r}\right)
$$

As in the small strain case, by substituting equation (26) into equation (22), a differential equation is obtained, whose integration leads to the following relationship between the convergences at the cavity wall and at the elasto-plastic boundary (Yu \& Rowe, 1999)

$$
a_{0}^{\zeta \kappa+1}-a^{\zeta \kappa+1}=\rho_{0, \mathrm{ls}}^{\zeta \kappa+1}-\rho_{\mathrm{ls}}^{\zeta \kappa+1}
$$

which for $\kappa=1$ expresses the incompressibility condition (equation (2)). If equations (4) and (9) are taken into account and

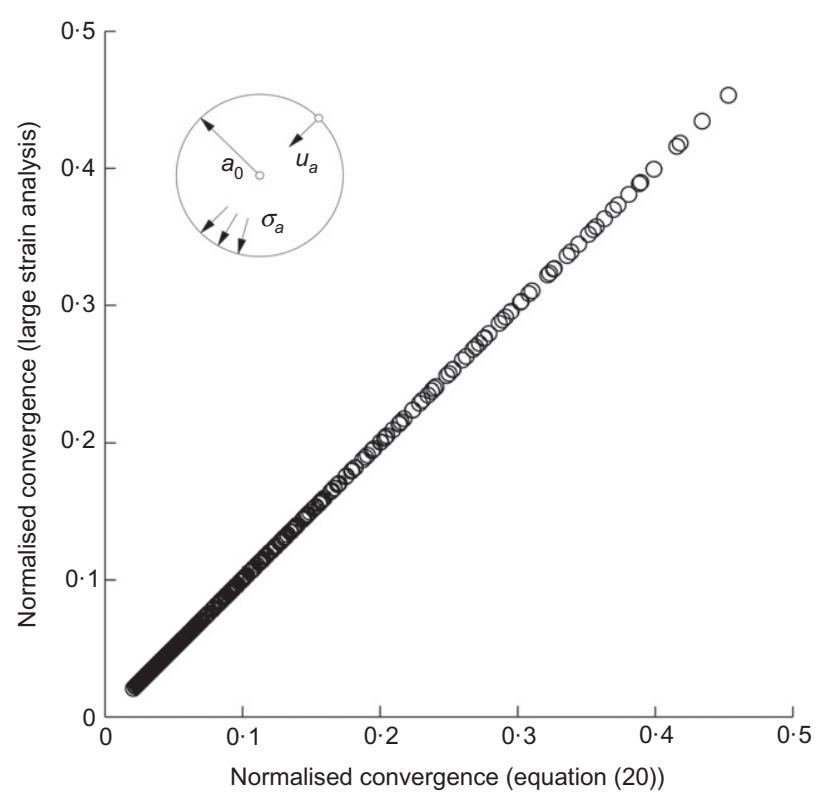

Fig. 10. Relationship between exact large strain convergences and corrected small strain convergences (equation (20)) under plane strain rotationally symmetric $(\zeta=1)$ and spherically symmetric $(\zeta=2)$ conditions (128 parameter sets; material constants as in Fig. 8; computational method after Vrakas \& Anagnostou (2014))

the second and higher order terms in the resulting binomial series are neglected (since strains in the elastic zone are small), that is, $\left(1+\varepsilon_{t \rho, \mathrm{ls}}\right)^{\zeta \kappa+1} \cong 1+(\zeta \kappa+1) \varepsilon_{t \rho, \mathrm{ls}}$, equation (27) gives

$$
\begin{aligned}
a_{0}^{\zeta \kappa+1}-a^{\zeta \kappa+1} & =\left[\left(1+\frac{u_{\rho, \mathrm{ls}}}{\rho_{\mathrm{ls}}}\right)^{\zeta \kappa+1}-1\right] \rho_{\mathrm{ls}}^{\zeta \kappa+1} \\
& \cong(\zeta \kappa+1) \varepsilon_{\mathrm{t} \rho, \mathrm{ls}} \rho_{\mathrm{ls}}^{\zeta \kappa+1}
\end{aligned}
$$

and thus

$$
U_{a, \mathrm{ls}}=1-\frac{1}{\left[1+(\zeta \kappa+1) \varepsilon_{t \rho, \mathrm{ls}}\left(\frac{\rho_{\mathrm{ls}}}{a}\right)^{\zeta \kappa+1}\right]^{1 /(\zeta \kappa+1)}}
$$

Equations (25) and (29), together with equations (18) and (19), which hold irrespective of the plastic flow and the problem geometry, lead to equation (20). Finally, the extent of plastification is determined from the small strain solution through the following relationship (after equations (19) and (20))

$$
\frac{\rho_{\mathrm{ls}}}{\rho_{\mathrm{ss}}}=1-U_{a, \mathrm{ls}}=\frac{1}{\left[1+(\zeta \kappa+1) U_{a, \mathrm{ss}}\right]^{1 /(\zeta \kappa+1)}}
$$

which shows that the plastic radius is also overestimated by small strain theory.

It should be mentioned, in closing, that even though it was necessary for proving equation (20) to assume that elastic deformations in the plastic zone are negligible (see equation (22)), this assumption is not essential with regard to the accuracy of the relationship. More specifically, equation (20) relates exact small strain to exact large strain convergences. This can be shown through a parametric study using the rigorous analytical solutions for the ground response curve. Fig. 10 presents exact large strain convergences (vertical axis) and those obtained by means of equation (20), that is, by 'self-correcting' the exact small strain convergences (horizontal axis). The results are in perfect agreement, lying on the angle bisector.

\section{NOTATION}

$\begin{aligned} a & \text { current tunnel radius } \\ a_{0} & \text { initial tunnel radius } \\ c & \text { cohesion } \\ E & \text { Young's modulus }\end{aligned}$ 
$F$ indefinite integral of the function $1 /\left[\sigma_{r}-f\left(\sigma_{r}\right)\right]$

$f$ arbitrary function of minor principal stress

$h$ hyperbolic function

$K_{0} \quad$ earth pressure coefficient at rest

$p_{\mathrm{w} 0}$ in situ pore water pressure

$r$ radius of a material point

$r_{0}$ initial radius of a material point

$U_{a}$ normalised tunnel convergence $\left(=u_{a} / a_{0}\right)$

$u$ radial displacement of a material point

$u_{a}$ radial displacement at tunnel wall

$u_{\mathrm{c}} \quad$ vertical displacement at crown of a tunnel

$u_{\mathrm{i}} \quad$ vertical displacement at invert of a tunnel

$u_{\mathrm{w}}$ horizontal displacement at side walls of a tunnel

$u_{\rho}$ radial displacement at elasto-plastic boundary

$z$ longitudinal distance from tunnel face

$\varepsilon_{r}, \varepsilon_{f}$ radial and tangential strain

$\varepsilon_{r}^{\mathrm{pl}}, \varepsilon_{t}^{\mathrm{pp}} \quad$ radial and tangential plastic strain

$\varepsilon_{t \rho} \quad$ tangential strain at elasto-plastic boundary

$\zeta$ variable indicating type of cavity $(\zeta=1$ cylindrical, $\zeta=2$ spherical)

$\kappa$ loosening factor (function of dilation angle)

$v$ Poisson ratio

$\rho$ radius of plastic zone

$\rho_{0}$ radius of plastic zone in undeformed state

$\sigma_{0}$ in situ isotropic stress

$\sigma_{a} \quad$ support pressure

$\sigma_{\mathrm{D}} \quad$ uniaxial compressive strength

$\sigma_{\mathrm{m} 0}$ mean in-plane in situ stress

$\sigma_{r}, \sigma_{t}$ radial and tangential Cauchy stress

$\sigma_{\rho}$ radial stress at elasto-plastic boundary

$\varphi$ friction angle

$\psi$ dilation angle

\section{SUBSCRIPTS}

ls large strain value

ss small strain value

\section{REFERENCES}

Anagnostou, G. (2014). Some critical aspects of subaqueous tunnelling (Muir Wood lecture 2014). Lausanne, Switzerland: International Tunnelling and Underground Space Association (ITA/AITES).

Anagnostou, G., Pimentel, E. \& Cantieni, L. (2008). AlpTransit Gotthard Basistunnel, Teilabschnitt Sedrun, Felsmechanische Laborversuche Los 378, Schlussbericht, Bericht Nr. 080109. Zurich, Switzerland: Institut für Geotechnik, ETH Zürich (in German).

Barla, G. (2002). Tunnelling under squeezing rock conditions. In Advances in geotechnical engineering and tunnelling (ed D. Kolymbas), pp. 169-268. Berlin, Germany: Logos Verlag.

Barla, G., Bonini, M. \& Semeraro, M. (2011). Analysis of the behaviour of a yield-control support system in squeezing rock. Tunnelling Underground Space Technol. 26, No. 1, 146-154.

Belytschko, T., Liu, W. K., Moran, B. \& Elkhodary, K. I. (2014). Nonlinear finite elements for continua and structures, 2 nd edn. Chichester, UK: Wiley.

Cantieni, L. \& Anagnostou, G. (2009). The interaction between yielding supports and squeezing ground. Tunnelling Underground Space Technol. 24, No. 3, 309-322.

Clausen, J., Damkilde, L. \& Andersen, L. (2007). An efficient return algorithm for non-associated plasticity with linear yield criteria in principal stress space. Comput. Structs 85, No. 23-24, 1795-1807.

Darling, P. (1992). Fifth time is proving lucky at Yacambú. Tunnels Tunnelling 24, No. 10, 17-19.

Dassault Systèmes (2012). Abaqus 6.12 - theory manual and analysis user's manual. Vélizy Villacoublay, France: Dassault Systèmes.

Dong, W., Pimentel, E. \& Anagnostou, G. (2013). Experimental investigations into the mechanical behaviour of the breccias around the proposed Gibraltar Strait tunnel. Rock Mech. Rock Engng 46, No. 5, 923-944.

Hill, R. (1950). The mathematical theory of plasticity. London, UK: Oxford University Press.

Hoek, E. \& Guevara, R. (2009). Overcoming squeezing in the Yacambú-Quibor tunnel, Venezuela. Rock Mech. Rock Engng 42, No. 2, 389-418.

Kovári, K. (1985). The determination of the characteristic line from straight line nomogramms. In Proceedings of the 5th international conference on numerical methods in geomechanics (eds T. Kawamoto and Y. Itikawa), pp. 1741-1746. Rotterdam, the Netherlands: Balkema.

Kovári, K. (1998). Tunnelling in squeezing rock. Tunnel 98, No. 5, $12-31$.

Kovári, K., Amberg, F. \& Ehrbar, H. (2000). Mastering of squeezing rock in the Gotthard Base. World Tunnelling 13, No. 5, 234-238.

Lee, E. H. (1969). Elastic-plastic deformation at finite strains. J. Appl. Mech. 36, No. 1, 1-6.

Lombardi, G., Neuenschwander, M. \& Panciera, A. (2009). Gibraltar tunnel project update - the geomechanical challenges. Geomech. Tunnelling 2, No. 5, 578-590.

Mair, R. J. (2008). Tunnelling and geotechnics: new horizons. Géotechnique 58, No. 9, 695-736, http://dx.doi.org/ 10.1680/geot.2008.58.9.695.

Pan, X. D. (1988). Numerical modelling of rock movements around mine openings. $\mathrm{PhD}$ thesis, Imperial College London, UK.

Pan, X. D., Hudson, J. A. \& Cassie, J. (1989). Large deformation of weak rocks at depth - a numerical case study. In Rock at great depth (eds V. Maury and D. Fourmaintraux), pp. 613-620. Rotterdam, the Netherlands: Balkema.

Schürch, R. \& Anagnostou, G. (2012). The applicability of the ground response curve to tunnelling problems that violate rotational symmetry. Rock Mech. Rock Engng 45, No. 1, 1-10.

Simo, J. C. \& Hughes, T. J. R. (1998). Computational inelasticity. New York, NY, USA: Springer-Verlag.

Standing, J. R. \& Potts, D. M. (2008). Contributions to Géotechnique 1948-2008: Tunnelling. Géotechnique 58, No. 5, 391-398, http:// dx.doi.org/10.1680/geot.2008.58.5.391.

Vermeer, P. A. \& de Borst, R. (1984). Non-associated plasticity for soils, concrete and rock. Heron 29, No. 3, 1-64.

Vogelhuber, M. (2007). Der Einfluss des Porenwasserdrucks auf das mechanische Verhalten kakiritisierter Gesteine. Dissertation Nr. 17079, Institut für Geotechnik, ETH Zürich, Zurich, Switzerland (in German).

Vrakas, A. \& Anagnostou, G. (2014). A finite strain closed-form solution for the elastoplastic ground response curve in tunnelling. Int. J. Numer. Analyt. Methods Geomech. 38, No. 11, $1131-1148$.

Vrakas, A. \& Anagnostou, G. (2015). Finite strain elastoplastic solutions for the undrained ground response curve in tunnelling. Int. J. Numer. Analyt. Methods Geomech. 39, No. 7, 738-761.

Yu, H. S. \& Rowe, R. K. (1999). Plasticity solutions for soil behaviour around contracting cavities and tunnels. Int. J. Numer. Analyt. Methods Geomech. 23, No. 12, 1245-1279. 